Article

\title{
Broad-Spectrum Cephalosporin-Resistant Klebsiella spp. Isolated from Diseased Horses in Austria
}

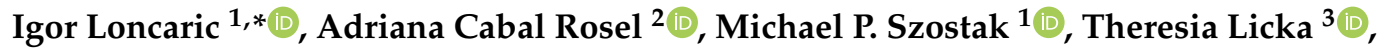 \\ Franz Allerberger ${ }^{2}$, Werner Ruppitsch ${ }^{2}$ and Joachim Spergser ${ }^{1}$ \\ 1 Institute of Microbiology, University of Veterinary Medicine, 1210 Vienna, Austria; \\ michael.szostak@vetmeduni.ac.at (M.P.S); Joachim.spergser@vetmeduni.ac.at (J.S.) \\ 2 Institute of Medical Microbiology and Hygiene, Austrian Agency for Health and Food Safety, 1090 Vienna, \\ Austria; adriana.cabal-rosel@ages.at (A.C.R.); franz.allerberger@ages.at (F.A.); \\ werner.ruppitsch@ages.at (W.R.) \\ 3 Clinical Unit of Equine Surgery, University of Veterinary Medicine, 1210 Vienna, Austria; \\ theresia.licka@vetmeduni.ac.at \\ * Correspondence: igor.loncaric@vetmeduni.ac.at; Tel.: +43-1-250772115
}

Received: 30 January 2020; Accepted: 15 February 2020; Published: 20 February 2020

Simple Summary: Broad-spectrum cephalosporin-resistant Klebsiella pneumoniae is considered as a serious problem for public human health. To date, only a few broad-spectrum cephalosporin-resistant Klebsiella have been isolated from horses. Considering the zoonotic potential of the Klebsiella spp., and the close relationship between man and horse, this study intended to generate data on the genetic background of broad-spectrum cephalosporin-resistant Klebsiella spp. isolated from horses in Austria. Overall, samples isolated between 2012 and 2019 from 1541 horses underwent bacteriological testing, resulting in 51 specimens tested positive for Klebsiella ssp. Antimicrobial susceptibility tests revealed that seven Klebsiella ssp. isolates were not only cefotaxime-resistant but also showed resistance against other classes of antibiotics so that they were considered to be multidrug-resistant. Data from whole genome sequencing and mating experiments strongly suggest that the majority of antibiotic resistance genes is encoded on plasmids in these seven multidrug-resistant Klebsiella ssp. Considering the potential threat when commensal Klebsiella inhabiting a healthy human gut acquire new antibiotic resistances due to the exchange of plasmids with multidrug-resistant Klebsiella ssp. from horses, further monitoring of horses and other domestic animals for the presence of broad-spectrum cephalosporin-resistant Klebsiella, not only in Austria but worldwide is therefore advisable.

\begin{abstract}
The aim of the present study was to investigate the diversity of broad-spectrum cephalosporin-resistant Klebsiella spp. isolated from horses in Austria that originated from diseased horses. A total of seven non-repetitive cefotaxime-resistant Klebsiella sp. isolates were obtained during diagnostic activities from autumn 2012 to October 2019. Antimicrobial susceptibility testing was performed. The isolates were genotyped by whole-genome sequencing (WGS). Four out of seven Klebsiella isolates were identified as K. pneumoniae, two as K. michiganensis and one as K. oxytoca. All isolates displayed a multi-drug resistant phenotype. The detection of resistance genes reflected well the phenotypic resistance profiles of the respective isolates. All but one isolate displayed the extended-spectrum $\beta$-lactamases (ESBL) phenotype and carried CTX-M cefotaximases, whereas one isolate displayed an ESBL and AmpC phenotype and carried cephamycinase (CMY)-2 and sulfhydryl variable (SHV)-type $b$ and Temoniera (TEM) $\beta$-lactamases. Among Klebsiella pneumoniae isolates, for different sequence types (ST) could be detected (ST147, ST307, ST1228, and a new ST4848). Besides resistance genes, a variety of virulence genes, including genes coding for yersiniabactin were detected. Considering the high proximity between horses and humans, our results undoubtedly identified a public health issue. This deserves to be also monitored in the years to come.
\end{abstract}


Keywords: AmpC; ESBL; Klebsiella pneumoniae; antibiotic-resistance; $\beta$-lactamases; horses

\section{Introduction}

Among the member of the genus Klebsiella, broad-spectrum cephalosporin-resistant Klebsiella (K.) pneumoniae is frequently associated with severe nosocomial infections in humans, and due to its antibiotic-resistant traits, infections leave limited therapeutic options [1,2]. In early 2017, the World Health Organization (WHO) listed carbapenem-resistant and 3rd generation cephalosporin-resistant Enterobacteriales (including, e.g., K. pneumoniae, Escherichia coli, Enterobacter spp., Serratia spp., Proteus spp., Providencia spp., Morganella spp.) "Priority 1: Critical group" bacterial pathogens. These bacteria are in focus on the discovery and development of new antibiotics [2,3].

Today, broad-spectrum cephalosporin-resistant K. pneumoniae is recognized as a serious public health problem in human medicine [4,5]. Contrarily, there is still a scarcity of information on broad-spectrum cephalosporin-resistant K. pneumoniae and members of the genus Klebsiella isolated from horses and other domestic animals. To date, only a few equine broad-spectrum cephalosporin-resistant Klebsiella have been isolated and characterized [4,6-10]. Recent studies reported that some of the characterized resistant K. pneumoniae isolates of equine origin were human-associated multidrug-resistant (MDR) K. pneumoniae [4,8]. At present, there are no published data on the genetic background of broad-spectrum cephalosporin-resistant Klebsiella spp. isolated from horses in Austria. Therefore, there is a need to generate such data to understand the molecular epidemiology of these particular pathogens.

In the present study, we have characterized a collection of equine broad-spectrum cephalosporin-resistant Klebsiella sp. from clinical samples by multiphasic approach, including whole-genome sequencing (WGS).

\section{Materials and Methods}

At the Institute of Microbiology, University of Veterinary Medicine, Vienna, approximately 350 susceptibility tests are performed on clinical isolates from horses each year. During the study period (2012 until October 2019), samples of 1541 horses underwent bacteriological testing. In 51 specimens, Klebsiella sp. was detected, wherefrom a total of seven non-repetitive cefotaxime-resistant isolates, which were identified to the species level by matrix-assisted laser desorption/ionization-time-of-flight (MALDI-TOF) mass spectrometry (Bruker Daltonik, Heidelberg, Germany), and were further analyzed. They originated from lavage (isolates 1505 and 2826), wound (isolates 2668 and 2742), fistula (isolate 1635), trachea (isolate 2341b), and feces (isolate 4545). All isolates were stored in glycerol stocks at $-80{ }^{\circ} \mathrm{C}$. All samples originated from non-food producing horses. All these clinical samples were received from third parties and, therefore, not subject to reporting obligations of the Ethics and Animal Welfare Commission of the University of Veterinary Medicine in Vienna.

Antimicrobial susceptibility testing was performed by agar disk-diffusion according to standards of the Clinical and Laboratory Standards Institute (CLSI) [11]. Escherichia coli ATCC ${ }^{\circledR}$ 25922 served as quality control strains. The following antimicrobials were used: cefotaxime, ceftazidime, aztreonam, imipenem, meropenem, gentamicin, amikacin, tobramycin, ciprofloxacin, trimethoprim-sulfamethoxazole, tetracycline, chloramphenicol, and fosfomycin (Becton Dickinson, Heidelberg, Germany). In addition, isolates were checked for extended-spectrum $\beta$-lactamase (ESBL) production by ESBL-test via agar disk diffusion [11]. Furthermore, cefoxitin $(30 \mu \mathrm{g})$ was added to this test to detect AmpC phenotypes.

Whole-genome sequencing (WGS) was performed by isolating and sequencing bacterial DNA, as previously described [12]. De novo assembly of raw reads, whole genome sequencingt (WGS) data analysis, including multi-locus sequence typing (MLST) and core genome multi-locus sequence-based typing (cgMLST), were performed, as previously described $[13,14]$. 
Species identification was conducted with the JSpecies workspace using the ANIb (average nucleotide identity via Basic Local Alignment Search Tool (BLAST) analysis tool [15]. The identification of acquired resistance genes and chromosomal mutations was performed using the Comprehensive Antibiotic Resistance Database (CARD; https://card.mcmaster.ca/home) [16], as well as ResFinder 3.2 (https://cge.cbs.dtu.dk/services/ResFinder/) [17] were used. eBURST (Based Upon Related Sequence Types) analysis (a plugin at https://bigsdb.pasteur.fr/) was conducted to identify clonal complexes (CCs), defined as groups of two or more independent isolates sharing identical alleles at six or more loci.

The presence of plasmids was determined using PlasmidFinder 1.3 available from the Center for Genomic Epidemiology web server (http://www.genomicepidemiology.org/) [18]. Probability Prediction of the location of a given antibiotic resistance gene was achieved by applying mlplasmids trained on K. pneumonia [19]. Posterior probability scores $>0.7$ and a minimum contig length of $1000 \mathrm{bp}$ indicate that a given contig is plasmid-derived.

Mating experiments were conducted by conjugation as well as transformation, as previously described [20]. Variable regions of class 1 and class 2 integrons were determined by PCR [20]. The quinolone resistance-determining regions (QRDR) of gyr $A$ and parC in ciprofloxacin-resistant isolates were amplified by PCR and sequenced [21].

The presence of virulence genes was examined by using the virulence allele library from the Institute Pasteur BIGSdb database for K. pneumoniae (http://bigsdb.pasteur.fr/klebsiella).

This whole-genome shotgun project has been deposited in DDBJ/EMBL/GenBank under the project number PRJNA600879. Raw sequence data for each strain were deposited under Sequence Read Archive (SRA) accession numbers SRR10899218 to SRR10899224.

\section{Results}

Four out of seven cefotaxime-resistant Klebsiella isolates were identified as K. pneumoniae, two as K. michiganensis, and one as K. oxytoca (Table 1). All but one isolate displayed the ESBL phenotype, whereas one isolate displayed an ESBL and AmpC phenotype. Besides cefotaxime, all K. pneumoniae isolates were resistant to ceftazidime, and one isolate additionally to aztreonam. All examined isolates were resistant to gentamicin and tobramycin. None of the analyzed isolates was resistant to carbapenems and amikacin. Five isolates were resistant to tetracycline, doxycycline, and chloramphenicol, whereas six were resistant to trimethoprim-sulfamethoxazole. All K. pneumoniae isolates were resistant to ciprofloxacin, and one isolate to fosfomycin (Table 1). Hence, all examined isolates were considered to be multidrug-resistant [22]. The detection of resistance genes reflected well the phenotypic resistance profiles of the examined isolates (Table 1). In two ciprofloxacin-resistant K. pneumoniae isolates, beside fluoroquinolone resistance genes $\operatorname{oq} x A, \operatorname{oq} x B, q r n B 1$, and $a a c\left(6^{\prime}\right)-I b-c r$, mutations in the quinolone resistance-determining regions (QRDRs) of the genes gyr $A$ and parC were observed (Table 1). Three isolates, both $K$. michiganensis isolates and the $K$. oxytoca isolate contained a class 1 integron with a variable part of ca. $1.7 \mathrm{~kb}$ in size, which harbored an aadA5 and a $d f r 17$ cassette.

In total, ten different plasmids IncFIA(HI1), IncFIB(K), IncFIB(pHCM2), IncHI1A, IncHI1B(R27), IncI1, IncN, IncQ1, IncR, and Col4401 were identified (Table 2). They shared between 92.11 and $100 \%$ DNA similarity with corresponding reference sequences. A K. michiganensis isolate and two K. pneumoniae isolates carried IncFIA(HI1), IncFIB(pHCM2), IncHI1A, IncHI1B(R27), and IncQ1. The K. oxytoca isolate carried IncI1 and IncN, whereas a K. pneumoniae carried IncN and IncR and another K. michiganensis $\operatorname{IncFIB}(\mathrm{K})$. According to mlplasmids analyses, the majority of resistance genes might be located on plasmids, especially all $b l a_{\mathrm{CTX}}, b l a_{\mathrm{TEM}}$, and $b l a_{\mathrm{OXA}}$ genes as well as all detected genes for resistance against aminoglycosides, trimethoprim/sulfamethoxazole, or chloramphenicol (Table 1).

Among virulence factors, K. pneumoniae type 3 fimbriae encoded by mrk operon genes as well iut A (aerobactin siderophores receptor) were detected in all K. pneumoniae isolates, whereas genes coding for yersiniabactin $(y b t)$ were detected in only one isolate (Table 3). 
Table 1. Characteristics of seven examined cefotaxime-resistant Klebsiella isolates.

\begin{tabular}{|c|c|c|c|c|c|c|c|c|c|c|c|c|c|c|c|}
\hline & & 1505 & & 1635 & & $2341 b$ & & 2668 & & 2742 & & 2826 & & 4545 & \\
\hline $\begin{array}{l}\mathrm{ST}^{1} \\
\mathrm{CT}^{3} \\
\text { Origin }\end{array}$ & & $\begin{array}{c}\text { K. } \\
\text { michiganensis } \\
\text { n.a. }{ }^{2} \\
\text { n.a. } \\
\text { Lavage }\end{array}$ & 4 مחת & $\begin{array}{c}\text { K. oxytoca } \\
\text { n.a. } \\
\text { n.a. } \\
\text { Fistula }\end{array}$ & קסת & $\begin{array}{c}\text { K. } \\
\text { pneumoniae } \\
\text { ST4848 } \\
\text { CT4643 } \\
\text { Trachea }\end{array}$ & קחס & $\begin{array}{c}\text { K. } \\
\text { pneumoniae } \\
\text { ST1228 } \\
\text { CT4644 } \\
\text { Wound }\end{array}$ & & $\begin{array}{c}\text { K. } \\
\text { pneumoniae } \\
\text { ST147 } \\
\text { ST1202 } \\
\text { Wound }\end{array}$ & & $\begin{array}{c}\text { K. } \\
\text { michiganensis } \\
\text { n.a. } \\
\text { n.a. } \\
\text { Lavage }\end{array}$ & & $\begin{array}{c}\text { K. } \\
\text { pneumoniae } \\
\text { ST307 } \\
\text { CT4645 } \\
\text { Feces }\end{array}$ & \\
\hline & & & $\mathrm{PPP}^{4}$ & & PPP & & PPP & & PPP & & PPP & & PPP & & PPP \\
\hline \multirow[b]{2}{*}{$\beta$-lactamas } & $\mathrm{P}^{5}$ & CTX & & CTX & & $\begin{array}{l}\text { CTX, } \\
\text { CAZ, } \\
\text { FOX }\end{array}$ & & $\begin{array}{l}\text { CTX } \\
\text { CAZ }\end{array}$ & & $\begin{array}{l}\text { CTX, } \\
\text { CAZ, } \\
\text { ATM }\end{array}$ & & CTX & & $\begin{array}{l}\text { CTX, } \\
\text { CAZ }\end{array}$ & \\
\hline & $\mathrm{G}^{6}$ & $\frac{b l a_{\text {СТХ-М-1 }}{ }^{7}}{b l a_{\mathrm{OXY}-4-1}}$ & $\begin{array}{l}0.745 \\
0.009\end{array}$ & $\begin{array}{l}b l a_{\mathrm{CTX}-\mathrm{M}-1} \\
b l a_{\mathrm{OXY}-2-7} \\
b l a_{\mathrm{TEM}-1 \mathrm{~B}}\end{array}$ & $\begin{array}{l}0.710 \\
0.003 \\
0.891\end{array}$ & $\frac{b l a_{\mathrm{CMY} 2}}{b l a_{\mathrm{SHV}}}$ & $\begin{array}{c}\text { nо ppp } \\
0.003 \\
0.965\end{array}$ & $\begin{array}{l}b l a_{\mathrm{CTX}-\mathrm{M}-1} \\
b l a_{\mathrm{SHV}-11} \\
b l a_{\mathrm{TEM}-1 \mathrm{~B}}\end{array}$ & $\begin{array}{c}0.760 \\
0.001 \\
\text { по ppp }\end{array}$ & $\begin{array}{c}b a_{\mathrm{CTX}-\mathrm{M}-15} \\
\text { lla }_{\mathrm{OXA}-1} \\
b a_{\mathrm{SHV}-11} \\
b l a_{\mathrm{TEM}-1 \mathrm{~B}}\end{array}$ & $\begin{array}{l}0.973 \\
0.961 \\
0.001 \\
0.973\end{array}$ & $\begin{array}{l}b l a_{\mathrm{CTX}-\mathrm{M}-1} \\
b l a_{\mathrm{OXY}-4-1}\end{array}$ & $\begin{array}{l}0.753 \\
0.004\end{array}$ & $\begin{array}{c}b l a_{\mathrm{CTX}-\mathrm{M}-15} \\
b l a_{\mathrm{OXA}-1} \\
b l a_{\mathrm{SHV}-28} \\
b l a_{\mathrm{TEM}-1 \mathrm{~B}} \\
\end{array}$ & $\begin{array}{l}0.976 \\
0.961 \\
0.002 \\
0.776\end{array}$ \\
\hline \multirow[b]{2}{*}{ Aminoglycosides } & $\mathrm{P}$ & GEN, TOB & & $\begin{array}{l}\text { GEN, } \\
\text { TOB }\end{array}$ & & $\begin{array}{l}\text { GEN, } \\
\text { TOB }\end{array}$ & & $\begin{array}{l}\text { GEN, } \\
\text { TOB }\end{array}$ & & $\begin{array}{l}\text { GEN, } \\
\text { TOB }\end{array}$ & & $\begin{array}{l}\text { GEN, } \\
\text { TOB }\end{array}$ & & $\begin{array}{l}\text { GEN, } \\
\text { TOB }\end{array}$ & \\
\hline & G & $\begin{array}{c}\text { aac(3)-IId } \\
\text { aadA5 } \\
\text { aph(3")-Ib } \\
a p h\left(3^{\prime}\right)-I a \\
\text { aph(6)-Id }\end{array}$ & $\begin{array}{c}0.854 \\
0.993 \\
0.896 \\
\text { no ppp } \\
0.896\end{array}$ & $\begin{array}{l}\text { aac(3)-IId } \\
\text { aadA5 } \\
\text { aph(3")-Ib } \\
\text { aph(6)-Id }\end{array}$ & $\begin{array}{l}0.909 \\
0.955 \\
0.895 \\
0.895\end{array}$ & $\begin{array}{l}a a c(3)-I I a \\
a p h\left(3^{\prime \prime}\right)-I b\end{array}$ & $\begin{array}{l}0.956 \\
0.956\end{array}$ & aac(3)-IId & 0.92 & $\begin{array}{l}a a c(3)-I I a \\
a a c\left(6^{\prime}\right)-I b-c r \\
a p h\left(3^{\prime \prime}\right)-I b \\
a p h(6)-I d\end{array}$ & $\begin{array}{l}0.963 \\
0.961 \\
0.973 \\
0.973\end{array}$ & $\begin{array}{c}\text { aac(3)-IId } \\
\text { aadA5 } \\
\text { aph(3")-Ib } \\
\text { aph(3')-Ia } \\
\text { aph(6)-Id }\end{array}$ & $\begin{array}{c}0.921 \\
0.986 \\
0.895 \\
\text { no ppp } \\
0.895\end{array}$ & $\begin{array}{l}\text { aac(3)-IIa } \\
a a c\left(6^{\prime}\right)-I b-c r \\
a p h\left(3^{\prime \prime}\right)-I b \\
a p h(6)-I d\end{array}$ & $\begin{array}{l}0.992 \\
0.961 \\
0.976 \\
0.976\end{array}$ \\
\hline \multirow[t]{2}{*}{ Tetracyclines } & $\mathrm{P}$ & TET, DOX & & $\begin{array}{l}\text { TET, } \\
\text { DOX }\end{array}$ & & & & & & $\begin{array}{l}\text { TET, } \\
\text { DOX }\end{array}$ & & $\begin{array}{l}\text { TET, } \\
\text { DOX }\end{array}$ & & $\begin{array}{l}\text { TET, } \\
\text { DOX }\end{array}$ & \\
\hline & G & $\operatorname{tet}(\mathrm{B})$ & 0.690 & tet(B) & 0.545 & & & & & tet(A) & 0.029 & $\operatorname{tet}(\mathrm{B})$ & 0.709 & tet(A) & 0.946 \\
\hline \multirow[t]{2}{*}{ Chloramphenicol } & $\mathrm{P}$ & $\mathrm{CHL}$ & & $\mathrm{CHL}$ & & & & & & $\mathrm{CHL}$ & & $\mathrm{CHL}$ & & $\mathrm{CHL}$ & \\
\hline & G & catA1 & 0.993 & catA1 & 0.945 & & & & & catB3 & 0.961 & catA1 & 0.986 & catB3 & 0.961 \\
\hline \multirow[b]{2}{*}{$\begin{array}{l}\text { Trimethoprim/ } \\
\text { sulfamethoxazole }\end{array}$} & $\mathrm{P}$ & SXT & & SXT & & SXT & & & & SXT & & SXT & & SXT & \\
\hline & G & $\begin{array}{c}\text { sul1 } \\
\text { sul2 } \\
\text { dfrA17 }\end{array}$ & $\begin{array}{l}0.993 \\
0.896 \\
0.993\end{array}$ & $\begin{array}{c}\text { sul1 } \\
\text { sul2 } \\
\text { dfrA17 }\end{array}$ & $\begin{array}{l}0.955 \\
0.895 \\
0.955\end{array}$ & $\begin{array}{c}\text { sul2 } \\
\text { dfrA14 }\end{array}$ & $\begin{array}{l}0.956 \\
0.876\end{array}$ & & & $\begin{array}{c}\text { sul2 } \\
\text { dfrA14 }\end{array}$ & $\begin{array}{l}0.973 \\
0.968\end{array}$ & $\begin{array}{c}\text { sul1 } \\
\text { sul2 } \\
\text { dfrA17 }\end{array}$ & $\begin{array}{l}0.986 \\
0.895 \\
0.986\end{array}$ & $\begin{array}{c}\text { sul2 } \\
\text { dfrA14 }\end{array}$ & $\begin{array}{l}0.976 \\
0.957\end{array}$ \\
\hline
\end{tabular}


Table 1. Cont.

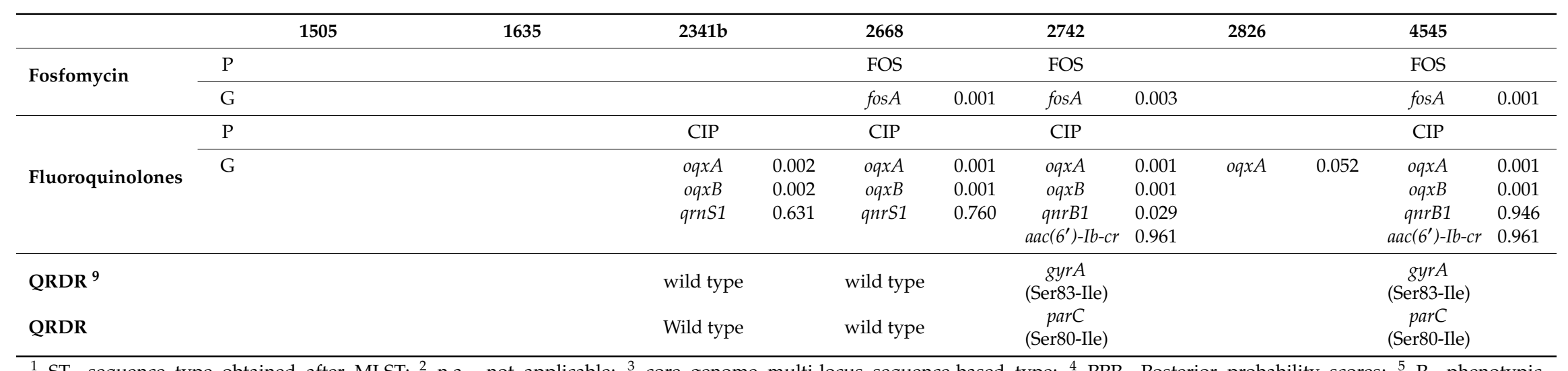

${ }^{1}$ ST-sequence type obtained after MLST; ${ }^{2}$ n.a.-not applicable; ${ }^{3}$ core genome multi-locus sequence-based type; ${ }^{4}$ PPP—Posterior probability scores; ${ }^{5}$ P—phenotypic resistance: CTX-cefotaxime, CAZ-ceftazidime, FOX-cefoxitin, ATM-aztreonam, GEN-gentamicin, TOB-tobramycin, TET-tetracycline, DOX-doxycycline, CHL-chloramphenicol, SXT-trimethoprim/sulfamethoxazole, CIP-ciprofloxacin; ${ }^{6}$ G-genotypic resistance; ${ }^{7}$ bold and underline—-detected on transconjugats/transformants; ${ }^{8}$ bold—-within class 1 integron; ${ }^{9}$ mutation in gyrA and parC of quinolone resistance-determining region (QRDR). 
Table 2. Identified plasmids in Klebsiella isolates.

\begin{tabular}{|c|c|c|c|}
\hline ID & Plasmid & Identity & Accession Number \\
\hline \multirow{5}{*}{1505} & IncFIA(HI1) & 100.0 & AF250878 \\
\hline & IncFIB(pHCM2) & 96.49 & AL513384 \\
\hline & IncHI1A & 99.52 & AF250878 \\
\hline & IncHI1B(R27) & 100.0 & AF250878 \\
\hline & IncQ1 & 100.0 & M28829.1 \\
\hline \multirow{5}{*}{1635} & IncFIA(HI1) & 100 & AF250878 \\
\hline & IncFIB(pHCM2) & 96.49 & AL513384 \\
\hline & IncHI1A & 99.52 & AF250878 \\
\hline & IncHI1B(R27) & 100 & AF250878 \\
\hline & IncQ1 & 100 & M28829.1 \\
\hline \multirow{2}{*}{$2341 b$} & IncI1 & 100 & AP005147 \\
\hline & IncN & 99.61 & AY046276 \\
\hline \multirow{2}{*}{2668} & IncN & 100 & AY046276 \\
\hline & IncR & 100 & DQ449578 \\
\hline 2742 & Col440I & 92.11 & СР023920.1 \\
\hline \multirow{5}{*}{2826} & IncFIA(HI1) & 100 & AF250878 \\
\hline & IncFIB(pHCM2) & 96.49 & AL513384 \\
\hline & IncHI1A & 99.52 & AF250878 \\
\hline & IncHI1B(R27) & 100 & AF250878 \\
\hline & IncQ1 & 100 & M28829 \\
\hline \multirow{2}{*}{4545} & $\operatorname{IncFIB}(\mathrm{K})$ & 98.93 & JN233704 \\
\hline & Col440I & 94.74 & СР023920.1 \\
\hline
\end{tabular}

Table 3. Identified virulence factors in four K. pneumoniae isolates. Numbers correspond to the exact alleles detected.

\begin{tabular}{|c|c|c|c|c|c|}
\hline Virulence Gene & $2341 b$ & 2668 & 2742 & 4545 & \\
\hline iut $A$ & new allele & new allele & new allele & new allele & aerobactin transport \\
\hline$m r k A$ & 2 & 2 & 6 & 12 & \multirow{8}{*}{$\begin{array}{c}\text { type } 3 \text { fimbrial gene } \\
\text { cluster }\end{array}$} \\
\hline$m r k B$ & 33 & 2 & 3 & 2 & \\
\hline$m r k C$ & new allele & 2 & 2 & new allele & \\
\hline$m r k D$ & 1 & 12 & 12 & 8 & \\
\hline$m r k F$ & new allele & 8 & 8 & 4 & \\
\hline$m r k H$ & 10 & 7 & 7 & 2 & \\
\hline$m r k I$ & 7 & 15 & 15 & 4 & \\
\hline$m r k J$ & 19 & 12 & 12 & 2 & \\
\hline$y b t A$ & & 1 & & & \multirow{11}{*}{ yersiniabactin } \\
\hline$y b t E$ & & 4 & & & \\
\hline$y b t P$ & & 4 & & & \\
\hline$y b t Q$ & & 22 & & & \\
\hline$y b t S$ & & 6 & & & \\
\hline$y b t T$ & & 1 & & & \\
\hline ybtu & & 14 & & & \\
\hline$y b t X$ & & 15 & & & \\
\hline fyuA & & 17 & & & \\
\hline irp1 & & 44 & & & \\
\hline irp2 & & 37 & & & \\
\hline
\end{tabular}

All four K. pneumoniae isolates belonged to different sequence types (ST) and cgMLST complex type (CT) (ST147-CT1202, ST307-CT4645, ST1228-CT4644 and a new ST4848-4643). These ST belonged 
to 4 clonal complexes: CC147 (ST147), CC37 (ST1228), CC307 (ST307) and CC702 (new ST4848). The minimum number of allelic differences between the isolates was 3686 .

\section{Discussion}

The present study demonstrates that broad-spectrum cephalosporin-resistant members of the genus Klebsiella are present in the Austrian horse population, although the prevalence in clinical samples seems to be low. These findings are in accordance with previous studies describing the presence of these particular bacteria in horse populations of other countries [4,6-10]. Moreover, a previous study carried out in 2018 on clinical samples from Austrian patients reported 8.4\% of K. pneumoniae isolates as resistant to third-generation cephalosporins [23].

In the present study, the most prevalent cefotaximase type was CTX-M- 1 carried by all three Klebsiella species identified; this $\beta$-lactamase is commonly associated with Enterobacteriales from livestock [24]. CTX-M-15, the dominating cefotaximase, is considered the most common ESBL in K. pneumoniae from humans and animals worldwide [4]. To the best of our knowledge, the present study describes for the first time CTX-M-1 producing K. michiganensis, a close relative of K. oxytoca. One K. pneumoniae isolate that displayed both the AmpC and ESBL phenotype carried three different $\beta$-lactamases, $b l a_{\mathrm{CMY} 2}, b l a_{\mathrm{SHV} 11}$, and $b l a_{\mathrm{TEM}-1}$. $b l a_{\mathrm{CMY} 2}$ was carried by an IncI1 conjugative plasmid. K. pneumoniae carrying plasmid-borne AmpC cephalosporinases (pAmpC) is a rare observation [6,25].

Another important observation is the co-existence of an arsenal of virulence factors and antibiotic resistance characters in one K. pneumoniae isolate (ST1228-CT4644). This isolate carried the yersiniabactin locus. Yersiniabactin is a siderophore, which is strongly associated with invasive clinical manifestations in humans [26]. Another siderophore, aerobactin, as well as type 3 fimbriae, which were detected in all K. pneumoniae isolates, may enhance colonization and adherence to host cells, invasiveness, and biofilm formation [27].

Among K. pneumoniae isolates examined, four different sequence types belonging to four different clonal complexes were identified. Two of these STs, ST147, and ST37, have been recognized as high-risk epidemic multiresistant human-associated clonal lineages [5]. ST147-CC147 is a human-related clone notorious for its multi-drug resistant character and harboring different $\beta$-lactamases, including carbapenemases [5]. Recently, this particular clone has emerged in companion animals [5,28]. In contrast, ST1228 has only one entry in the Institut Pasteur MLST database (http://bigsdb.pasteur.fr) and to our knowledge, had never been associated with horses. ST1228 belongs to CC 37 whose predicted founder is ST37. K. pneumoniae ST37 isolates have been associated with different resistance properties, including carbapenem and colistin resistance, and were isolated from humans and animals [5,29]. One fecal isolate analyzed in the present study belonged to ST307-CC307. ST307 is a relatively new but highly successful pandemic clone, which was previously recovered from human patients, and recent data suggest a multi-drug resistant character of this clone [30]. $\beta$-lactamase producing K. pneumoniae ST307 has also been detected among different animals [31]. In the present study, a new sequence type, ST4848, belonging to the clonal complex CC702 (predicted founder ST702), has been identified by eBURST analysis. CC702 is a rare clone that has never been associated with broad-spectrum cephalosporin-resistant K. pneumoniae of equine origin. Data generated in this study (mating experiments, PlasmidFinder analysis, posterior probability plasmid analysis) strongly suggest that the majority of resistance genes are plasmid-borne. All identified replicons (IncFIA(HI1), $\operatorname{IncFIB(K),~}$ IncFIB(pHCM2), IncHI1A, IncHI1B(R27), IncI1, IncN, IncQ1, IncR) are considered as vehicles of $b l a_{\mathrm{CTX}-\mathrm{M}-15}$ and $b l a_{\mathrm{CTX}-\mathrm{M}-1}$ dissemination in humans and animals $[5,32]$.

\section{Conclusions}

Even though the overall prevalence of broad-spectrum cephalosporin-resistant Klebsiella sp. among specimens of equine origin in Austria appears to be low, the proportion of broad-spectrum cephalosporin-resistant Klebsiella spp. vs. non-resistant Klebsiella spp. is worth mentioning, since commensal Klebsiella spp. can acquire antimicrobial resistance. As such, the broad-spectrum 
cephalosporin-resistant Klebsiella spp. especially in combination with other resistance properties, are of special clinical importance because of dramatically narrowing the possibility of antibiotic treatment. Due to the regular contact and proximity between horses and humans monitoring horses for the presence of cephalosporin-resistant Klebsiella spp. is advisable in order to prevent further spread of these zoonotic agents.

Author Contributions: Conceptualization, I.L., T.L. and J.S.; methodology, I.L., M.P.S. and W.R.; software, M.P.S.; validation, I.L. and M.P.S.; formal analysis, I.L., A.C.R. and W.R.; investigation, I.L., A.C.R., M.P.S. and W.R.; resources, F.A. and J.S.; data curation, I.L., A.C.R. and T.L.; writing-original draft preparation, I.L.; writing-review and editing, I.L., A.C.R., M.P.S., T.L., F.A., W.R. and J.S.; project administration, I.L., F.A., W.R., J.S.; funding acquisition, W.R. All authors have read and agreed to the published version of the manuscript.

Funding: Part of the sequencing-work was funded by a grant awarded under the "MedVetKlebs" Horizon 2020 Framework Programme H2020-SFS-2016-2017 (H2020-SFS-2017-1). Open Access Funding by the University of Veterinary Medicine Vienna.

Acknowledgments: We thank the team of curators of the Institut Pasteur MLST and whole genome MLST databases for curating the data and making them publicly available at http://bigsdb.pasteur.fr. We would also like to express our thanks to Michael Steinbrecher, Anna Stöger, and Barbara Tischler for technical assistance.

Conflicts of Interest: The authors declare no conflict of interest.

\section{References}

1. Mulani, M.S.; Kamble, E.E.; Kumkar, S.N.; Tawre, M.S.; Pardesi, K.R. Emerging Strategies to Combat ESKAPE Pathogens in the Era of Antimicrobial Resistance: A Review. Front. Microbiol. 2019, 10, 539. [CrossRef] [PubMed]

2. Woodford, N.; Turton, J.F.; Livermore, D.M. Multiresistant Gram-negative bacteria: The role of high-risk clones in the dissemination of antibiotic resistance. FEMS Microbiol Rev. 2011, 35, 736-755. [CrossRef] [PubMed]

3. WHO. Global Priority List of Antibiotic-Resistant Batceria to Guide Research, Discovery, and Development of New Antibiotics. 2017. Available online: http://www.who.int/medicines/publications/WHO-PPL-Short_ Summary_25Feb-ET_NM_WHO.pdf (accessed on 1 January 2020).

4. Ewers, C.; Stamm, I.; Pfeifer, Y.; Wieler, L.H.; Kopp, P.A.; Schønning, K.; Prenger-Berninghoff, E.; Scheufen, S.; Stolle, I.; Günther, S.; et al. Clonal Spread of Highly Successful ST15-CTX-M-15 Klebsiella pneumoniae in Companion Animals and Horses. J. Antimicrob. Chemother. 2014, 69, 2676-2680. [CrossRef] [PubMed]

5. Navon-Venezia, S.; Kondratyeva, K.; Carattoli, A. Klebsiella pneumoniae: A Major Worldwide Source and Shuttle for Antibiotic Resistance. FEMS Microbiol. Rev. 2017, 41, 252-275. [CrossRef]

6. Vo, A.T.T.; van Duijkeren, E.; Fluit, A.C.; Gaastra, W. Characteristics of Extended-Spectrum Cephalosporin-Resistant Escherichia coli and Klebsiella pneumoniae Isolates from Horses. Vet. Microbiol. 2007, 124, 248-255. [CrossRef]

7. Börjesson, S.; Greko, C.; Myrenås, M.; Landén, A.; Nilsson, O.; Pedersen, K. A Link between the Newly Described Colistin Resistance Gene Mcr-9 and Clinical Enterobacteriaceae Isolates Carrying BlaSHV-12 from Horses in Sweden. J. Glob. Antimicrob. Resist. 2019. [CrossRef]

8. Da Roza, F.T.; Couto, N.; Carneiro, C.; Cunha, E.; Rosa, T.; Magalhães, M.; Tavares, L.; Novais, Â.; Peixe, L.; Rossen, J.W.; et al. Commonality of Multidrug-Resistant Klebsiella pneumoniae ST348 Isolates in Horses and Humans in Portugal. Front. Microbiol. 2019, 10, 1657. [CrossRef]

9. Schmiedel, J.; Falgenhauer, L.; Domann, E.; Bauerfeind, R.; Prenger-Berninghoff, E.; Imirzalioglu, C.; Chakraborty, T. Multiresistant Extended-Spectrum $\beta$-Lactamase-Producing Enterobacteriaceae from Humans, Companion Animals and Horses in Central Hesse, Germany. BMC Microbiol. 2014, 14, 187. [CrossRef]

10. Shnaiderman-Torban, A.; Paitan, Y.; Arielly, H.; Kondratyeva, K.; Tirosh-Levy, S.; Abells-Sutton, G.; Navon-Venezia, S.; Steinman, A. Extended-Spectrum $\beta$-Lactamase-Producing Enterobacteriaceae in Hospitalized Neonatal Foals: Prevalence, Risk Factors for Shedding and Association with Infection. Animals 2019, 9, 600. [CrossRef]

11. Clinical and Laboratory Standards Institute. Performance Standards for Antimicrobial Susceptibility Testing, 26th ed.; CLSI supplement M100S; CLSI: Wayne, PA, USA, 2016; pp. 74-80. 
12. Lepuschitz, S.; Huhulescu, S.; Hyden, P.; Springer, B.; Rattei, T.; Allerberger, F.; Mach, R.L.; Ruppitsch, W. Characterization of a Community-Acquired-MRSA USA300 Isolate from a River Sample in Austria and Whole Genome Sequence Based Comparison to a Diverse Collection of USA300 Isolates. Sci. Rep. 2018, 8, 9467. [CrossRef]

13. Bankevich, A.; Nurk, S.; Antipov, D.; Gurevich, A.A.; Dvorkin, M.; Kulikov, A.S.; Lesin, V.M.; Nikolenko, S.I.; Pham, S.; Prjibelski, A.D.; et al. SPAdes: A New Genome Assembly Algorithm and Its Applications to Single-Cell Sequencing. J. Comput. Biol. 2012, 19, 455-477. [CrossRef] [PubMed]

14. Lepuschitz, S.; Schill, S.; Stoeger, A.; Pekard-Amenitsch, S.; Huhulescu, S.; Inreiter, N.; Hartl, R.; Kerschner, H.; Sorschag, S.; Springer, B.; et al. Whole Genome Sequencing Reveals Resemblance between ESBL-Producing and Carbapenem Resistant Klebsiella pneumoniae Isolates from Austrian Rivers and Clinical Isolates from Hospitals. Sci. Total Environ. 2019, 662, 227-235. [CrossRef] [PubMed]

15. Richter, M.; Rosselló-Móra, R.; Oliver Glöckner, F.; Peplies, J. JSpeciesWS: A Web Server for Prokaryotic Species Circumscription Based on Pairwise Genome Comparison. Bioinformatics 2016, 32, 929-931. [CrossRef] [PubMed]

16. Alcock, B.P.; Raphenya, A.R.; Lau, T.T.Y.; Tsang, K.K.; Bouchard, M.; Edalatmand, A.; Huynh, W.; Nguyen, A.-L.V.; Cheng, A.A.; Liu, S.; et al. CARD 2020: Antibiotic Resistome Surveillance with the Comprehensive Antibiotic Resistance Database. Nucleic Acids Res. 2019, 48, D517-D525. [CrossRef] [PubMed]

17. Zankari, E.; Hasman, H.; Cosentino, S.; Vestergaard, M.; Rasmussen, S.; Lund, O.; Aarestrup, F.M.; Larsen, M.V. Identification of Acquired Antimicrobial Resistance Genes. J. Antimicrob. Chemother. 2012, 67, 2640-2644. [CrossRef]

18. Carattoli, A.; Zankari, E.; Garcì-Fernandez, A.; Larsen, M.; Lund, O.; Villa, L.; Aarestrup, F.; Hasman, H. PlasmidFinder and PMLST: In Silico Detection and Typing of Plasmids. Antimicrob. Agents Chemother. 2014, 58, 3895-3903. [CrossRef]

19. Arredondo-Alonso, S.; Rogers, M.R.C.; Braat, J.C.; Verschuuren, T.D.; Top, J.; Corander, J.; Willems, R.J.L.; Schürch, A.C. Mlplasmids: A User-Friendly Tool to Predict Plasmid- and Chromosome-Derived Sequences for Single Species. Microb. Genom. 2018, 4. [CrossRef]

20. Desvars-Larrive, A.; Ruppitsch, W.; Lepuschitz, S.; Szostak, M.P.; Spergser, J.; Feßler, A.T.; Schwarz, S.; Monecke, S.; Ehricht, R.; Walzer, C.; et al. Urban Brown Rats (Rattus Norvegicus) as Possible Source of Multidrug-Resistant Enterobacteriaceae and Meticillin-Resistant Staphylococcus Spp., Vienna, Austria, 2016 and 2017. Eurosurveillance 2019, 24. [CrossRef]

21. Loncaric, I.; Beiglböck, C.; Feßler, A.T.; Posautz, A.; Rosengarten, R.; Walzer, C.; Ehricht, R.; Monecke, S.; Schwarz, S.; Spergser, J.; et al. Characterization of ESBL- and AmpC-Producing and Fluoroquinolone-Resistant Enterobacteriaceae Isolated from Mouflons (Ovis orientalis musimon) in Austria and Germany. PLoS ONE 2016, 11, e0155786. [CrossRef]

22. Sweeney, M.T.; Lubbers, B.V.; Schwarz, S.; Watts, J.L. Applying Definitions for Multidrug Resistance, Extensive Drug Resistance and Pandrug Resistance to Clinically Significant Livestock and Companion Animal Bacterial Pathogens. J. Antimicrob. Chemother. 2018, 73, 1460-1463. [CrossRef]

23. European Centre for Disease Prevention and Control. Surveillance of Antimicrobial Resistance in Europe Annual Report of the European Antimicrobial Resistance Surveillance Network (EARS-Net) 2018; European Centre for Disease Prevention and Control: Solna kommun, Sweden, 2019. [CrossRef]

24. Ewers, C.; Bethe, A.; Semmler, T.; Guenther, S.; Wieler, L.H. Extended-Spectrum $\beta$-Lactamase-Producing and AmpC-Producing Escherichia coli from Livestock and Companion Animals, and Their Putative Impact on Public Health: A Global Perspective. Clin. Microbiol. Infect. 2012, 18, 646-655. [CrossRef] [PubMed]

25. Madec, J.Y.; Haenni, M.; Nordmann, P.; Poirel, L. Extended-spectrum $\beta$-lactamase/AmpC- and carbapenemase-producing Enterobacteriaceae in animals: A threat for humans? Clin. Microbiol. Infect. 2017, 23, 826-833. [CrossRef] [PubMed]

26. Holt, K.E.; Wertheim, H.; Zadoks, R.N.; Baker, S.; Whitehouse, C.A.; Dance, D.; Jenney, A.; Connor, T.R.; Hsu, L.Y.; Severin, J.; et al. Genomic Analysis of Diversity, Population Structure, Virulence, and Antimicrobial Resistance in Klebsiella pneumoniae, an Urgent Threat to Public Health. Proc. Natl. Acad. Sci. USA 2015, 112, E3574-E3581. [CrossRef] [PubMed]

27. Clegg, S.; Murphy, C.N. Epidemiology and Virulence of Klebsiella pneumoniae. Microbiol. Spectr. $2016,4$. [CrossRef] 
28. Ovejero, C.M.; Escudero, J.A.; Thomas-Lopez, D.; Hoefer, A.; Moyano, G.; Montero, N.; Martin-Espada, C.; Gonzalez-Zorn, B. Highly Tigecycline-Resistant Klebsiella pneumoniae Sequence TYPE 11 (ST11) \& ST147 Isolates from Companion Animals. Antimicrob. Agents Chemother. 2017, 61, e02640-e02716. [CrossRef]

29. Taniguchi, Y.; Maeyama, Y.; Ohsaki, Y.; Hayashi, W.; Osaka, S.; Koide, S.; Tamai, K.; Nagano, Y.; Arakawa, Y.; Nagano, N. Co-Resistance to Colistin and Tigecycline by Disrupting MgrB and RamR with IS Insertions in a Canine Klebsiella pneumoniae ST37 Isolate Producing SHV-12, DHA-1 and FosA3. Int. J. Antimicrob. Agents 2017, 50, 697-698. [CrossRef]

30. Wyres, K.L.; Hawkey, J.; Hetland, M.A.K.; Fostervold, A.; Wick, R.R.; Judd, L.M.; Hamidian, M.; Howden, B.P.; Löhr, I.H.; Holt, K.E. Emergence and Rapid Global Dissemination of CTX-M-15-Associated Klebsiella pneumoniae Strain ST307. J. Antimicrob. Chemother. 2019, 74, 577-581. [CrossRef]

31. Harada, K.; Shimizu, T.; Mukai, Y.; Kuwajima, K.; Sato, T.; Usui, M.; Tamura, Y.; Kimura, Y.; Miyamoto, T.; Tsuyuki, Y.; et al. Phenotypic and Molecular Characterization of Antimicrobial Resistance in Klebsiella Spp. Isolates from Companion Animals in Japan: Clonal Dissemination of Multidrug-Resistant Extended-Spectrum $\beta$-Lactamase-Producing Klebsiella pneumoniae. Front. Microbiol. 2016, 7, 1021. [CrossRef]

32. Carattoli, A. Plasmids and the Spread of Resistance. Int. J. Med. Microbiol. 2013, 303, 298-304. [CrossRef]

(C) 2020 by the authors. Licensee MDPI, Basel, Switzerland. This article is an open access article distributed under the terms and conditions of the Creative Commons Attribution (CC BY) license (http://creativecommons.org/licenses/by/4.0/). 